\title{
Description of Xenorhabdus khoisanae sp. nov., the symbiont of the entomopathogenic nematode Steinernema khoisanae
}

\author{
Tiarin Ferreira \\ Department of Conservation Ecology and Entomology, University of Stellenbosch, Private Bag X1, 7602 Matieland, \\ South Africa
}

Carol A. van Reenen

DSMZ - Deutsche Sammlung von Mikroorganismen und Zellkulturen, Inhoffenstrasse 7B, 38124 Braunschweig, Germany

Akihito Endo

DSMZ - Deutsche Sammlung von Mikroorganismen und Zellkulturen, Inhoffenstrasse 7B, 38124 Braunschweig, Germany

\section{Cathrin Spröer}

DSMZ - Deutsche Sammlung von Mikroorganismen und Zellkulturen, Inhoffenstrasse 7B, 38124 Braunschweig, Germany

\section{Antoinette P. Malan}

Department of Conservation Ecology and Entomology, University of Stellenbosch, Private Bag X1, 7602 Matieland, South Africa

Leon M. T. Dicks

DSMZ - Deutsche Sammlung von Mikroorganismen und Zellkulturen, Inhoffenstrasse 7B, 38124 Braunschweig, Germany

\begin{abstract}
Bacterial strain $\mathrm{SF}^{\top} 7^{\top}$, and additional strains SF80, SF362 and 106-C, isolated from the nematode Steinernema khoisanae, are non-bioluminescent Gram-reaction-negative bacteria that share many of the carbohydrate fermentation reactions recorded for the type strains of recognized Xenorhabdus species. Based on $16 \mathrm{~S}$ rRNA gene sequence data, strain $\mathrm{SF} 87^{\top}$ is shown to be closely related ( $98 \%$ similarity) to Xenorhabdus hominickii DSM $17903^{\top}$. Nucleotide sequences of strain SF87 obtained from the recA, dnaN, gltX, gyrB and infB genes showed $96-97 \%$ similarity with Xenorhabdus miraniensis DSM 17902'. However, strain SF87 shares only $52.7 \%$ DNA-DNA relatedness with the type strain of $X$. miraniensis, confirming that it belongs to a different species. Strains SF87 ${ }^{\top}$, SF80, SF362 and 106-C are phenotypically similar to $X$. miraniensis and $X$. beddingii, except that they do not produce acid from aesculin. These strains are thus considered to represent a novel species of the genus Xenorhabdus, for which the name Xenorhabdus khoisanae sp. nov. is proposed. The type strain is SF87 ${ }^{\top}\left(=\mathrm{DSM} 25463^{\top}=\right.$ ATCC BAA-2406 $^{\top}$ ).
\end{abstract}

Xenorhabdus species are bound in obligate alliance of mutual benefit with specific species of entomopathogenic nematodes of the family Steinernematidae (Thomas \& Poinar, 1979). Thus far, 65 Steinernema species have been described worldwide, of which Steinernema khoisanae (Nguyen et al., 2006) was isolated in the Western Cape province of South Africa. Thomas \& Poinar (1979) were the first to describe symbiotic bacteria in Steinernema as members of the genus Xenorhabdus. Since then, 23 species in the genus Xenorhabdus have been described as listed in Fig. 1 and Table 1. In this paper, we describe a novel symbiont, Xenorhabdus khoisanae sp. nov., associated with the entomopathogenic nematode $S$. khoisanae collected in South Africa. 
Bacterial strains SF87 ${ }^{\top}$, SF80, SF362 and 106-C were isolated from different S. khoisanae nematode populations, as previously described (Malan et al., 2006, 2011). Cultures were obtained indirectly from the nematodes by sampling the haemocoel of wax moth larvae (Galleria mellonella L.), which was plated onto nutrient agar (Biolab Diagnostics), supplemented with $0.004 \%(\mathrm{w} / \mathrm{v})$ triphenyltetrazolium chloride and $0.025 \%(\mathrm{w} / \mathrm{v})$ bromothymol blue (NBTA) according to the procedure described by Akhurst (1980). Plates were incubated at $26^{\circ} \mathrm{C}$ for $72 \mathrm{~h}$ and blue-green colonies were randomly selected for identification and further characterization.

Isolates of Xenorhabdus species were also routinely cultured in trypticase soy broth (TSB; Beckton Dickinson) and Luria broth (LB; Biolab), and stored in $40 \%$ (v/v) glycerol at $-80^{\circ} \mathrm{C}$. Xenorhabdus miraniensis DSM $17902^{\top}$, Xenorhabdus hominickii DSM $17903^{\top}$ and Bacillus subtilis subsp. subtilis DSM $10^{\top}$ were obtained from the DSMZ. Escherichia coli transformants were cultured in LB containing $100 \mu \mathrm{g}$ ampicillin $\mathrm{ml}^{-1}$. Bacillus subtilis subsp. subtilis DSM $10^{\top}$ was grown in nutrient broth (NB; Biolab).

Cell size measurements were taken by means of a Leica DM2000 research microscope (Leica Microsystems) equipped with a camera, computer and digital image software [Leica Application Suite (LAS), version 3.5.0]. Several phenotypic characteristics were determined, including Gram reactions. For colony pigmentation, isolates were streaked onto NBTA and MacConkey Agar (Biolab), and incubated for $48 \mathrm{~h}$ at $30^{\circ} \mathrm{C}$. To determine optimum temperature requirements for growth, isolates were grown overnight in LB at $26-42{ }^{\circ} \mathrm{C}\left(1{ }^{\circ} \mathrm{C}\right.$ increases). Optimum growth temperature for strain SF87 $7^{\top}$ was also determined in NB and TSB. Growth was measured spectrophotometrically at $600 \mathrm{~nm}$.

Sensitivity to ampicillin in LB was determined as described by Somogyi et al. (2002). Antimicrobial activity was tested by overlaying $48 \mathrm{~h}$ cultures of strains SF87 ${ }^{\top}$, SF80, SF362, 106-C, X. hominickii DSM $17902^{\top}$ and $X$. miraniensis DSM $17903^{\top}$ with an active growing culture of $B$. subtilis subsp. subtilis DSM $10^{\top}$. Lipase, DNase and lecithinase activities were determined as described by Ferreira et al. (2013). Haemolysis was observed by streaking the strains on agar plates containing either $10 \%(\mathrm{v} / \mathrm{v})$ sheep blood or $5 \%(\mathrm{v} / \mathrm{v})$ horse blood (National Health Laboratory Services). Plates were incubated at $30^{\circ} \mathrm{C}$ for $48 \mathrm{~h}$.

All tests were conducted in duplicate. Biochemical properties were recorded using Biolog GN microplates, and API $20 \mathrm{NE}$ and API $50 \mathrm{CH}$ test strips (bioMérieux). Test strips were incubated at $30^{\circ} \mathrm{C}$ for 10 days as indicated by Boemare \& Akhurst (1988). X. miraniensis DSM $17902^{\top}$ and $X$. hominickii DSM $17903^{\top}$ were included as reference strains in carbohydrate (API) reactions and agar plate phenotypic tests, except for ampicillin sensitivity. The possible presence of bioluminescence was determined by scanning the colonies with the Xenogen in vivo imaging system (IVIS; Caliper Life Sciences).

Total genomic DNA of overnight cultures of strains SF87' ${ }^{\top}$, SF80, SF362 and 106-C was extracted using a ZR fungal/bacterial DNA kit (Zymo Research). Isolates were initially identified by amplifying the 16S rRNA gene using primers as described by Brunel et al. (1997). Based on previous phylogenetic studies, the recombinase A (recA), DNA polymerase III beta chain ( $d n a N)$, glutamyl-tRNA synthetase catalytic subunit $(g / t X)$, DNA gyrase subunit B $(g y r B)$ and initiation factor $B($ inf $B)$ genes were amplified with primers recA1(F) and recA2(R), dnaN1(F) and dnaN2(R), gltX1(F) and gltX2(R), 8SF_gyrB(F) and 9Rev_gyrB(R), and infB1(F) and infB2(R), respectively (Tailliez et al., 2010, 2012).

An initial denaturation step of $94{ }^{\circ} \mathrm{C}$ for 4 min was used, followed by 35 cycles of $94{ }^{\circ} \mathrm{C}$ for 1 min, the appropriate temperature for each primer pair for $30 \mathrm{~s}$ and $72{ }^{\circ} \mathrm{C}$ for $1 \mathrm{~min}$. Final extension was at $72{ }^{\circ} \mathrm{C}$ for 7 min. TaKaRa Ex Taq, 10x Ex Taq buffer and dNTP mixture (Takara Bio) were used at concentrations recommended by the manufacturer. Amplified products were purified using a QIAquick PCR Purification kit (Qiagen), ligated into pGEM T-Easy vector (Promega), transformed into Escherichia coli, and plasmid preparations sequenced (DNA Sequencing unit, Central Analytical Facility, University of Stellenbosch) using the BigDye Teminator V3.1 sequencing kit (Applied Biosystems). Sequences were analysed using the blast program (NCBI). 
The $16 \mathrm{~S}$ rRNA gene sequences of strains SF87 ${ }^{\top}, \mathrm{SF} 80, \mathrm{SF} 362$ and $106-\mathrm{C}$ and related type strains were aligned using the program clustal $x$ ver. 1.18 (Thompson et al., 1997). Sequences of the closest relatives were retrieved from DDBJ. The Kimura two-parameter model was used to calculate distance matrices for the aligned sequences (Kimura, 1980) and bootstrapping with 1000 replicates was done to estimate the robustness of the individual branches (Felsenstein, 1985). For the 16S rRNA gene sequences, phylogenetic trees were reconstructed using the neighbour-joining (Saitou \& Nei, 1987) and maximum-likelihood methods in phylip ver. 3.65 software (Felsenstein, 2005). Partial recA, dnaN, gltX, gyrB and infB gene sequences were analysed using the neighbour-joining method. DNA-DNA hybridization between strain SF87 ${ }^{\top}$ and $X$. miraniensis DSM $17902^{\top}$ was performed according to Huss et al. (1983).

\section{Phenotypic characteristics of isolates SF87 ${ }^{\top}$, SF80, SF362 and 106-C}

All strains tested were Gram-reaction-negative and absorbed dye. Colonies were dark blue-green on NBTA and light reddish brown on MacConkey agar. None of the strains displayed bioluminescence. All the isolates were catalase- and oxidase-negative, and did not reduce nitrate. Optimum growth temperature in LB was $31-32{ }^{\circ} \mathrm{C}$, while a maximum growth temperature of $42^{\circ} \mathrm{C}$ was observed for strain SF87 in NB. Strains SF87 ${ }^{\top}$, SF80, SF362 and 106-C were inhibited by ampicillin in solid medium at concentrations higher than $50 \mu \mathrm{g} \mathrm{ml}^{-1}$, while slight variations in liquid medium were observed (SF87 ${ }^{\top}$, no growth above $50 \mu \mathrm{g}$ $\mathrm{ml}^{-1}$; SF80 and 106-C, no growth at $25 \mathrm{gg} \mathrm{ml}^{-1}$; SF362, no growth at $12.5 \mu \mathrm{g} \mathrm{ml}^{-1}$ ).

No lecithinase activity was observed for strains SF87 ${ }^{\top}$, SF80, SF362 and 106-C, but positive reactions were recorded for the reference strains. All four novel strains tested were negative for DNase activity. Lipase activity was not detected on plates containing Tween 20 or Tween 40, and variable results were recorded for plates containing Tween 60 and Tween 80 . Total haemolysis was observed for all strains on sheep and horse blood. All strains showed strong antimicrobial activity against B. subtilis subsp. subtilis DSM $10^{\top}$.

Biolog GN microplate reactions indicated that strain SF87 ${ }^{\top}$ utilized $\mathrm{N}$-acetylglucosamine, dl-lactic acid, bromosuccinic acid, I-alanine, I-alanine glycine, glycyl I-glutamic acid, I-histidine and I-serine. This matches Biolog GN results for most of the strains studied by Somvanshi et al. (2006). Strain SF87 ${ }^{\top}$ had a weak affinity for $d$-mannose, uridine, $p$-hydroxyphenylacetic acid and trehalose. Reactions recorded by Somvanshi et al. (2006) indicated that all strains tested utilized d-mannose, most strains utilized uridine and trehalose, while few utilized $p$-hydroxyphenylacetic acid.

According to the API $50 \mathrm{CH}$ system, strains SF87 ${ }^{\top}$, SF80, SF362, 106-C, $X$. miraniensis DSM $17902^{\top}$ and $X$. hominickii DSM $17903^{\top}$ produced acid from $\mathrm{N}$-acetylglucosamine, d-fructose, d-glucose, glycerol, maltose, $\mathrm{d}$-mannose and ribose. Acid production from inositol and 5-ketogluconate was weak. Acid production from trehalose was positive for strains SF87 ${ }^{\top}, 106-\mathrm{C}$ and the control strains, but only weakly positive for strains SF80 and SF362. Weak positive reactions on starch were recorded for strains SF87 ${ }^{\top}$ and $106-C$, while strains SF80 and SF362 were negative. A comparison of API results of strains SF87 ${ }^{\top}$, SF80, SF362 and 106-C with previously published data is presented in Table 1. Results from API 20 NE showed that all four novel strains and the two reference strains assimilated glucose, mannose, $\mathrm{N}$-acetylglucosamine, maltose and gluconate.

\section{Phylogenetic position of strains SF87 ${ }^{\top}$, SF80, SF362 and 106-C}

According to the Kimura two-parameter model, strains SF87 ${ }^{\top}$, SF80, SF362 and 106-C aligned with $97 \%$ similarity to the $16 \mathrm{~S}$ rRNA gene sequences of several Xenorhabdus type strains, clearly indicating that they belong to the same genus (Fig. S1, available in IJSEM Online). A similar tree topology was obtained by using maximum-likelihood analysis, with highest similarity (98.1\%) to X. hominickii DSM $17903^{\top}$ (Fig. S2).

In addition to $16 \mathrm{~S}$ rRNA gene sequence analysis, several recent studies have adopted a multi-gene approach to distinguish between Xenorhabdus species (Kuwata et al., 2013; Lee \& Stock, 2010; Tailliez et al., 2010, 2012). Lee \& Stock (2010) analysed the 16S rRNA gene and two housekeeping genes, 
phosphoserine aminotransferase and recA, while Tailliez et al. $(2010,2012)$ and Kuwata et al. (2013) used the genes recA, dnaN, gltX, gyrB and infB. In this study, partial recA, dnaN, gltX, gyrB and infB gene sequences of strains SF87 ${ }^{\top}$, SF80, SF362 and 106-C were analysed using the neighbour-joining method. The results show that these strains are phylogenetically closely related to $X$. miraniensis DSM $17902^{\top}(96-97 \%$ similarity; Figs S3-S7). This was confirmed by groupings obtained from concatenated sequences (5500 bp) of the six genes (96-97\% similarity; Fig. 1).

Strain SF87 shared only $52.7 \%$ DNA homology with $X$. miraniensis DSM $17902^{\top}$ by DNA-DNA hybridization analysis. This is below the $70 \%$ DNA-DNA relatedness threshold proposed by Wayne et al. (1987). Strains SF87 ${ }^{\top}$, SF80, SF362 and 106-C are thus regarded as isolates of a novel species of the genus Xenorhabdus, for which the name Xenorhabdus khoisanae sp. nov. is proposed.

\section{Description of Xenorhabduskhoisanae sp. nov.}

Xenorhabdus khoisanae (khoi.sa'na.e. N.L. gen. n. khoisanae of the Khoisan people, i.e. isolated from the lands these people occupy).

Cells are Gram-reaction-negative, catalase- and oxidase-negative, and rod-shaped (2-3×0.2-0.7 $\mu \mathrm{m})$. Growth is aerobic. Maximum growth temperature recorded is $42{ }^{\circ} \mathrm{C}$ in NB and $37^{\circ} \mathrm{C}$ in TSB. Colonies on MacConkey agar are light reddish-brown. Acid is produced from $\mathrm{N}$-acetylglucosamine, $\mathrm{d}$-fructose, $\mathrm{d}$ glucose, glycerol, maltose, $d$-mannose and ribose. Acid production from trehalose and starch is variable and negative from aesculin.

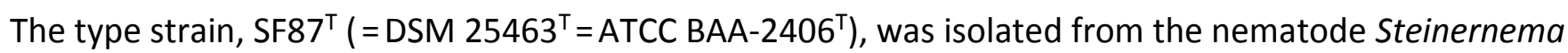
khoisanae. SF 80, 106-C and SF362, isolated from the same source, are additional strains of the species.

\section{Acknowledgements}

We thank the South African Apple and Pear Producers' Trust (SAAPPT), Citrus Research International (CRI), and the Technology, Human Resources for Industry Programme (THRIP) for funding of the project, and Zorina Daywood for technical assistance.

South African Apple and Pear Producers' Trust (SAAPPT)

Citrus Research International (CRI)

Technology, Human Resources for Industry Programme (THRIP)

The GenBank/EMBL/DDBJ accession numbers for the $16 \mathrm{~S}$ rRNA, dnaN, gltX, gyrB, recA and infB gene sequences of Xenorhabdus khoisanae sp. nov. SF87 ${ }^{\top}$ are HQ142625, AB685733-AB685736 and JX623984, respectively.

The GenBank/EMBL/DDBJ accession numbers for the 16S rRNA, recA, dnaN, gltX, gyrB and infB gene sequences of $X$. khoisanae sp. nov. SF 80, 106-C and SF362 are JX623966-JX623983, respectively.

Seven supplementary figures are available with the online version of this paper. 


\section{Table}

\begin{tabular}{|c|c|c|c|c|c|c|c|c|c|c|c|c|c|c|c|c|c|c|c|c|c|c|c|c|c|c|}
\hline & 1 & 2 & 3 & 4 & 5 & & $7 \mid$ & $\mid 9$ & 10 & 1 & 12 & 13 & 14 & 15 & 16 & 17 & 1 & 19 & 3 & 21 & 22 & & 24 & & & \\
\hline \multicolumn{27}{|c|}{ Acid production from (API 50CH E): } \\
\hline d-Ribose & + & + & & + & & 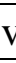 & - & & $\mathrm{v}$ & + & $\mathrm{v}$ & - & + & $\mathrm{v}$ & + & - & + & - & + & + & $\mathrm{v}$ & - & - & + & $\mathrm{v}$ & - \\
\hline Inositol & $\mathrm{w}$ & $\mathrm{w}$ & $\mathrm{w}$ & $\mathrm{w}$ & $\square$ & & + & $\mathrm{v}$ & - & - & $\mathrm{v}$ & + & $\mathrm{v}$ & - & - & - & - & - & + & - & $\mathrm{v}$ & - & $\mathrm{w}$ & + & $\mathrm{V}$ & - \\
\hline d-Sorbitol & - & - & -[ & - & & 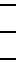 & $\square$ & - & - & - & - & - & - & - & - & - & - & - & - & - & - & - & - & - & $\mathrm{v}$ & - \\
\hline$N$-Acetylglucosamine & + & + & + & + & + & & $\mathrm{v}$ & $\mathrm{v}$ & $\mathrm{v}$ & - & + & $\mathrm{v}$ & + & + & + & - & - & - & + & + & + & + & + & + & $\mathrm{V}$ & + \\
\hline Aesculin & - & - & - & - & + & - & - & $\mathrm{v}$ & $\mathrm{v}$ & + & + & $\mathrm{V}$ & - & + & - & - & + & + & + & + & - & $\mathrm{v}$ & - & + & + & + \\
\hline Maltose & + & + & + & + & + & $\mathrm{v}$ & - & $\mathrm{v}$ & $\mathrm{v}$ & - & + & - & - & - & + & + & + & + & + & + & $\mathrm{v}$ & + & + & + & + & + \\
\hline Trehalose & + & $\mathrm{w}$ & $\mathrm{w}$ & +- & + & $\mathrm{v}$ & - & + & - & - & - & - & $\mathrm{v}$ & + & - & - & + & + & + & + & $\mathrm{v}$ & $\mathrm{v}$ & + & - & - & + \\
\hline Gluconate & + & + & + & + & + & $\mathrm{v}$ & - & & - & - & - & - & + & - & - & - & - & - & + & $\mathrm{w}$ & - & - & $\mathrm{w}$ & + & - & - \\
\hline 5-Keto gluconate & $\mathrm{w}$ & $\mathrm{w}$ & $\mathrm{w}$ & $\mathrm{w}$ & + & & + & - & $\mathrm{v}$ & $\mathrm{w}$ & + & + & + & $\mathrm{w}$ & + & + & - & - & $\mathrm{w}$ & $\mathrm{w}$ & $\mathrm{v}$ & $\mathrm{v}$ & $\mathrm{w}$ & $\mathrm{w}$ & - & + \\
\hline \multicolumn{27}{|c|}{ Assimilation of: (API $20 \mathrm{NE}$ ) } \\
\hline Glucose & + & - & + & +- & & & + & & + & + & + & + & + & - & + & - & + & + & + & + & + & + & + & + & + & + \\
\hline Mannose & + & - & + & +[ & + & & + & + & $\mathrm{V}$ & + & + & + & + & + & + & - & + & + & + & + & + & + & + & + & + & + \\
\hline$N$-Acetylglucosamine & + & + & + & + & + & + & + & + & + & + & + & + & + & + & + & - & + & + & + & + & + & + & + & + & + & + \\
\hline Maltose & + & + & + & +[ & + & + & $\mathrm{v}$ & + & + & + & + & + & + & - & + & - & + & + & + & + & + & + & \begin{tabular}{|l|}
+ \\
\end{tabular} & + & + & + \\
\hline Gluconate & + & + & + & + & + & + & $\mathrm{v}$ & + & $\mathrm{v}$ & + & + & + & + & + & + & - & $\mathrm{v}$ & - & + & + & $\mathrm{v}$ & + & + & + & + & + \\
\hline
\end{tabular}

Table 1. Comparison of acid production and assimilation by the four novel strains and the type strains of recognized Xenorhabdus species after 10 days incubation at $30^{\circ} \mathrm{C}$

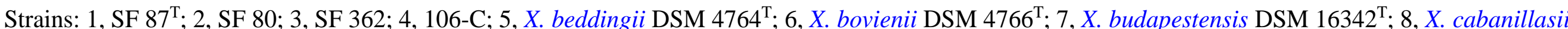

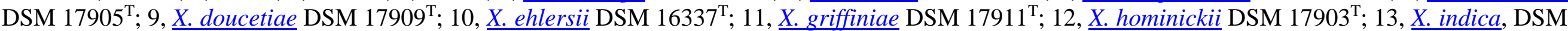

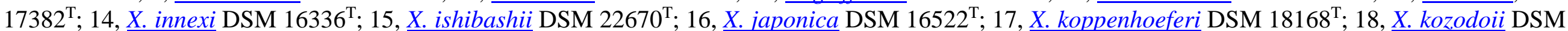

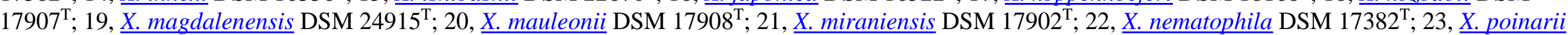
DSM $4768^{\mathrm{T}} ; 24, \underline{X}$. romanii $\mathrm{DSM} 17910^{\mathrm{T}} ; 25, \underline{X}$. stockiae $\mathrm{DSM} 17904^{\mathrm{T}} ; 26, \underline{X}$. szentirmaii $\mathrm{DSM} 16338^{\mathrm{T}} ; 27, \underline{X}$. vietnamensis $\mathrm{DSM} 22392^{\mathrm{T}}$. Data for the reference type strains are from Akhurst \& Boemare (1988), Kuwata et al. (2012), Lengyel et al. (2005), Nishimura et al. (1994), Somvanshi et al. (2006), Tailliez et al. $(2006,2010,2012)$ and Thomas \& Poinar (1979). +, Carbohydrate utilized; -, not utilized; w, weak reaction; v, variable reaction. 


\section{Figure}

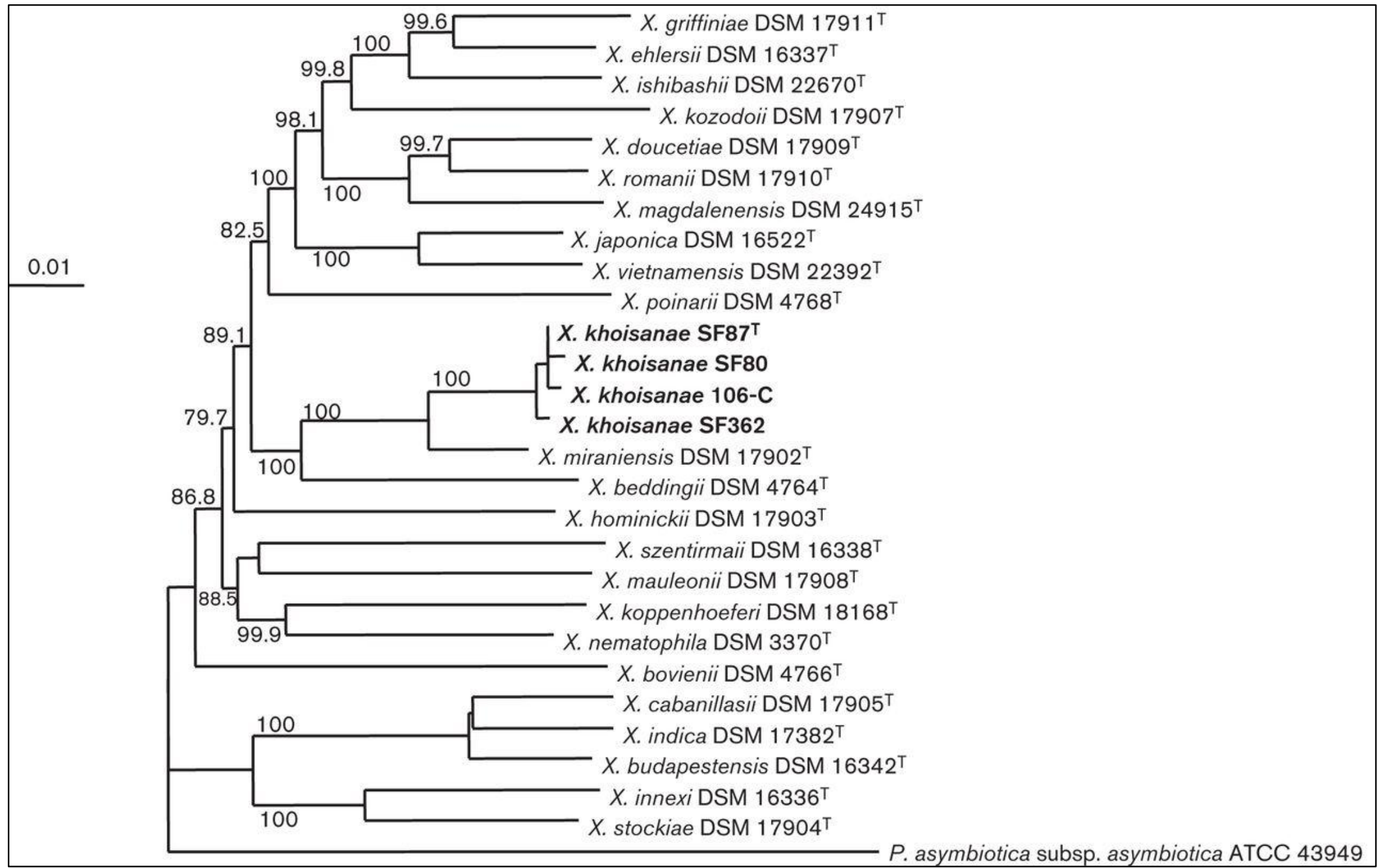

Fig. 1. Phylogenetic relationship of X. khoisanae strains SF87T, SF80, 106-C and SF362 to known Xenorhabdus species based on concatenated (16S rRNA, recA, dnaN, gltX, gyrB and infB) gene sequences.

The tree was constructed by the neighbour-joining method. Photorhabdus asymbiotica subsp. asymbiotica ATCC 43949 was used as an outgroup species. Bootstrap values above $70 \%$ are given at branch points. Bar, $10 \%$ sequence divergence. 